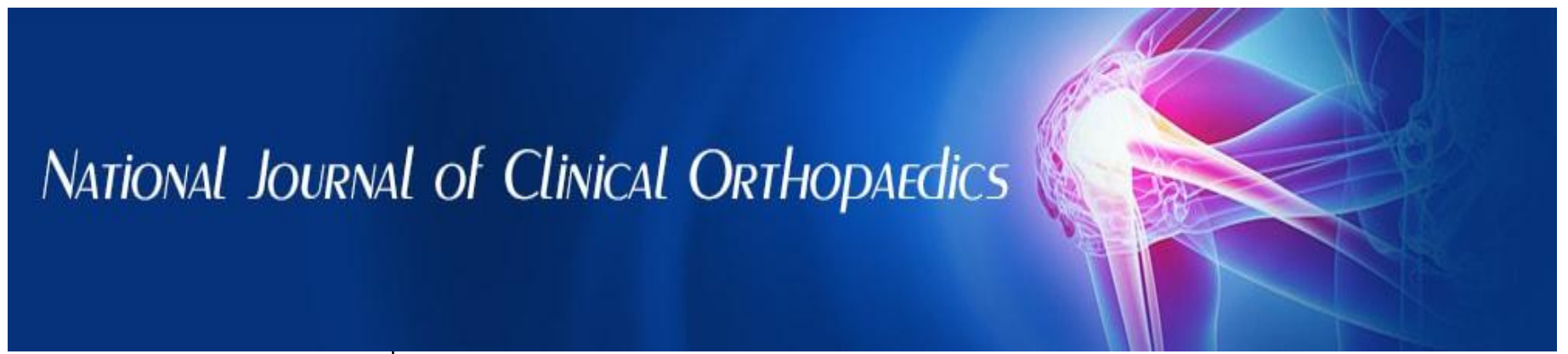

ISSN (P): 2521-3466

ISSN (E): 2521-3474

(C) Clinical Orthopaedics

www.orthoresearchjournal.com

2020; 4(3): 19-21

Received: 25-04-2020

Accepted: 02-07-2020

\section{Surinder Kumar}

Senior Resident, Department of orthopaedics, GMC Amritsar,

Punjab, India

\section{Rupinder Kaur}

MS Gynecologist, Medical officer CHC Lopoke Amritsar, Punjab, India
Corresponding Author: Rupinder Kaur

MS Gynecologist, Medical officer CHC Lopoke Amritsar, Punjab,

India

\section{Assessment of functional outcome of lower third tibial fracture fixation with distal tibial locking plate: An observational study}

\section{Surinder Kumar and Rupinder Kaur}

DOI: https://doi.org/10.33545/orthor.2020.v4.i3a.229

\section{Abstract}

Background: Fractures of the distal third shaft and distal metaphysis of tibia are one of the difficult and challenging problems faced by orthopaedic surgeons. These fractures are usually associated with fractures of the lower third of fibula which need to be addressed separately to get well aligned ankle mortis, unlike the proximal and mid third shafts fractures of tibia, where fibular fractures need not always be treated separately. Hence; the present study was planned for assessing the functional outcome of lower third tibial fracture fixation with distal tibial locking plate.

Materials \& methods: A total of 30 patients with lower third tibial fractures were enrolled. Preoperative clinical and radiographic examination of all the patients was carried out. Patients were prepared for locking plate fixation and pre-anaesthetic preparation was done. All the orthopaedic procedures of locking plate fixation were carried out under the hands of skilled and experienced orthopaedic surgeons. Follow-up was done and functional outcome was assessed on follow-up. Olerud-Molander functional evaluation score (OMFES) was used for evaluating the functional outcome on final follow-up. Complications, if any, were recorded separately.

Results: According to OMFES, while assessing the functional outcome, it was observed that excellent results were present in 20 percent of the cases while good results were present in 70 percent of the cases. Fair results were found to be present in 10 percent of the cases. Complications were found to be present in 23.33 percent of the cases. Malunion was found to be present in 1 case, while non-union was found to be present in 2 cases. Superficial infection was found to be present in 13.33 percent of the cases.

Conclusion: Even though distal locking plates are associated with good functional outcome, significant proportion of the patients show occurrence of postoperative complications. Hence; proper care should be while performing these orthopedic procedures for reducing complication rate.

Keywords: Complication, tibia, plates

\section{Introduction}

Fractures of the distal third shaft and distal metaphysis of tibia are one of the difficult and challenging problems faced by orthopaedic surgeons. The problems associated with these fractures are due to the fact that distal third shaft and distal metaphysis of tibia are relatively less vascular. Since this area is having less soft coverage, even relatively low energy injuries can result in severe soft tissue damage and communition of the fracture. These fractures are usually associated with fractures of the lower third of fibula which need to be addressed separately to get well aligned ankle mortis, unlike the proximal and mid third shafts fractures of tibia, where fibular fractures need not always be treated separately ${ }^{[1-3]}$. Nearby ankle joint (being a hinged type), poses unique problem. Any malunion disturbs the normal biomechanics of the ankle and foot, thereby leading to arthritis of the ankle and foot joints. The optimum management of such extra-articular pilon fractures is conjectural with no clear guidelines depicting treatment. Historically the closed fractures of lower tibia have been treated by closed reduction and casting other modalities include plating (open and minimal invasive), interlocking nail, external fixators including Ilizarov circular ring fixators. Even within the specific modality of treatment there exists many variations in the technique ${ }^{[4,5]}$. Hence; the present study was planned for assessing the functional outcome of lower third tibial fracture fixation with distal tibial locking plate. 


\section{Materials and Methods}

The present study was conducted with the aim of assessing the functional outcome of lower third tibial fracture fixation with distal tibial locking plate. A total of 30 patients with lower third tibial fractures were enrolled. Written consent was obtained from all the patients after explaining in detail the entire study protocol. Study period for the present research was from July 2014 to June 2016. Only those patients were included who underwent treatment for lower third tibial fracture fixation with distal tibial locking plate. Biplanar injury radiography was evaluated to determine the fracture location and involvement of distal part of tibia.

\section{Inclusion Criteria}

- Skeletally mature patients,

- Patients with negative history of any other systemic illness,

- Patients involving distal $5 \mathrm{~cm}$ of tibia and all closed and Gustilo-Anderson type 1 fractures,

- Patients with negative history of any known drug allergy

Complete demographic details of all the patients were obtained. Pre-operative clinical and radiographic examination of all the patients was carried out. Patients were prepared for locking plate fixation and pre-anaesthetic preparation was done. All the orthopaedic procedures of locking plate fixation were carried out under the hands of skilled and experienced orthopaedic surgeons. Follow-up was done and functional outcome was assessed on follow-up. Olerud- Molander functional evaluation score (OMFES) was used for evaluating the functional outcome on final follow-up ${ }^{[6]}$. Grading of this scoring system was as follows:

- Excellent: Score 91 to 100,

- Good: Score 61 to 90 ,

- Fair: Score 31 to 60 and

- Poor: Score of less than 30

Complications, if any, were recorded separately. All the results were recorded in Microsoft excel sheet and were analysed by SPSS software. Chi-square test and one way ANOVA were used for evaluation of level of significance.

\section{Results}

In the present study, a total of 30 patients were analyzed. Mean age of the patients was found to be 53.3 years respectively. 43.33 percent of the patients belonged to the age group of more than 50 years. 63.33 percent of the patients were males while the remaining were females. According to OMFES, while assessing the functional outcome, it was observed that excellent results were present in 20 percent of the cases while good results were present in 70 percent of the cases. Fair results were found to be present in 10 percent of the cases.

In the present study, overall, complications were found to be present in 23.33 percent of the cases. Malunion was found to be present in 1 case, while non-union was found to be present in 2 cases. Superficial infection was found to be present in 13.33 percent of the cases.

Table 1: Age-wise distribution

\begin{tabular}{|c|c|c|}
\hline Age group (years) & Number of patients & Percentage \\
\hline Less than 30 & 5 & 16.67 \\
\hline 30 to 50 & 12 & 40 \\
\hline More than 50 & 13 & 43.33 \\
\hline
\end{tabular}

Table 2: Gender-wise distribution

\begin{tabular}{|c|c|c|}
\hline Gender & Number of patients & Percentage \\
\hline Males & 19 & 63.33 \\
\hline Females & 11 & 36.67 \\
\hline
\end{tabular}

Table 3: Functional outcome according to OMFES

\begin{tabular}{|c|c|c|}
\hline Functional outcome & Number of patients & Percentage \\
\hline Excellent & 6 & 20 \\
\hline Good & 21 & 70 \\
\hline Fair & 3 & 10 \\
\hline Poor & 0 & 0 \\
\hline
\end{tabular}

Table 4: Complications

\begin{tabular}{|c|c|c|}
\hline Complications & Number of patients & Percentage \\
\hline Superficial infection & 4 & 13.33 \\
\hline Non-union & 2 & 6.67 \\
\hline Malunion & 1 & 3.33 \\
\hline
\end{tabular}

\section{Discussion}

The proximal tibia is triangular in shape with a vast metaphyseal region narrowing distally. The tibia shaft is a long bone that articulates with the talus, fibula and the distal femur. The vascular anatomy is extensive and dependent on the compartment of muscles it supplies. The anterior tibial artery is the first branch of the popliteal artery, passes between the 2 heads of the tibialis anterior and Extensor hallucis longus (EHL) terminating as the dorsalis pedis. The posterior tibial artery is a continuation of the popliteal artery coursing in the deep compartment of the leg terminating as the medial and lateral plantar arteries. The aim of the treatment of the distal tibial fractures is to achieve union of the fracture in normal alignment and regaining the stable, mobile and painless ankle joint while avoiding the infection and other complications ${ }^{[7-9]}$.

In the present study, a total of 30 patients were analyzed. Mean age of the patients was found to be 53.3 years respectively. 43.33 percent of the patients belonged to the age group of more than 50 years. 63.33 percent of the patients were males while the remaining were females. According to OMFES, while assessing the functional outcome, it was observed that excellent results were present in 20 percent of the cases while good results were present in 70 percent of the cases. Fair results were found to be present in 10 percent of the cases. Viberg B et al. evaluated the proportion of complications and the functional outcome following ORIF with low-profile locking plates in patients with distal tibia fractures. Retrospective data was retrieved using county databases, operation books, health record and X-ray images for 6 hospitals ( 1 level 1, 5 level 2) in the Region of Southern Denmark. Between January 2007 and April 201170 consecutive patients with 71 distal tibia fractures were treated with low-profile locking plate were included. The proportion of post-operative complications, classified as minor and major complications, was retrieved from electronic health records and patient interviews. Long-term functional outcome assessed by EuroQol EQ-5D-5L questionnaire, AOFAS Ankle-Hindfoot scale, and return to pre-injury job function through patient interview and examination. There were $3243 \mathrm{~A}, 543 \mathrm{~B}$ and 34 43C-fractures, 12 open and 10 high-energy fractures. Forty-nine cases $(69 \%)$ experienced complications during the follow-up time, of which 34 were minor complications and 15 were major complications. Median EQ-5D-5L index value was 0.76 , median EQ VAS-score was 80, and median AOFAS score was 73. Thirty-three percent of working patients had not returned to work as a result of the fracture. Their study suggested that treatment of distal tibia fractures with low-profile locking plates 
might have a higher proportion of complications and worse functional outcome than previously reported ${ }^{[9]}$. Rathod SR et al. assessed the functional outcome and complication rates of distal metaphyseal fracture. They have studied 40 patients in civil hospital Ahmedabad. Age range of the patients was 20-60 years. Most common mode of trauma in both the groups is road traffic accident. Associated fibula fracture was present in $18(90 \%)$ participants in group 1 (nailing) and $17(85 \%$ ) patients in group 2 (plating). Differences between two groups regarding duration of surgery were not significant. No significant intraoperative complications were noted in both groups. Time after which partial weight bearing and full weight bearing was started were significantly shorter in group-1 $(\mathrm{p}=0.005)$. The average time before union was 23.45 weeks (range, 16-36 weeks) in group 1 and 26 weeks (range,19-41 weeks), $(\mathrm{p}=0.09)$. Malalignment was found in $25 \%$ of patients in group 1 and $10 \%$ of patients in group 2. Angulation in group 1 was 3.4 degree (range, $0-12$ ) and 1.0 degree (range, $0-9)$ in group $2(\mathrm{p}=0.04)$. The overall results were comparable and most patients were satisfied with the results. These results indicated that both modalities of treatment deserve a place in treating distal metaphyseal fractures of tibia. ${ }^{10}$ In the present study, overall, complications were found to be present in 23.33 percent of the cases. Malunion was found to be present in 1 case, while non-union was found to be present in 2 cases. Superficial infection was found to be present in 13.33 percent of the cases. Hasani I et al. Presented the superior results of the two-stage minimally-invasive method using locking plate fixation, making this a historic step forward in treating distal tibia fractures. Twenty-three patients were finally included. In analysing the data collected, they focused their attention on the final functional outcomes as indicated by dorsiflexion nine months after injury and also according to the AOFAS AnkleHindfoot Scale. Results were excellent with no or minimal consequences. Where complications were present, these were benign and did not require further surgery. They believed that this modern method for the treatment of distal tibia fractures should be applied routinely and considered as the gold standard in this domain ${ }^{[11]}$.

\section{Conclusion}

From the above results, the authors concluded that even though distal locking plates are associated with good functional outcome, significant proportion of the patients show occurrence of postoperative complications. Hence; proper care should be while performing these orthopedic procedures for reducing complication rate.

\section{References}

1. Sarmiento A, Sharpe FE, Ebramzadeh E, Normand P, Shankwiler J. Factors influencing the outcome of closed tibial fractures treated with functional bracing. Clin Orthop Relat Res. 1995; 315:8-24.

2. Song P, Pu LLQ. The Soleus Muscle Flap: An Overview of Its Clinical Applications for Lower Extremity Reconstruction. Ann Plast Surg. 2018; 81(6S Suppl 1):S109-S116.

3. Bezstarosti H, Van Lieshout EMM, Voskamp LW, Kortram $\mathrm{K}$, Obremskey $\mathrm{W}$, McNally MA et al. Insights into treatment and outcome of fracture-related infection: a systematic literature review. Arch Orthop Trauma Surg. 2019; 139(1):61-72.

4. Blachut PA, O'Brien PJ, Meek RN, Broekhuyse HM. Interlocking intramedullary nailing with and without reaming treatment of closed fractures of the tibial shaft. A prospective, randomized study. J Bone Jt Surg Am. 1997; 79:640-646.

5. Joveniaux Pierre, Ohl Xavier, Harisboure Alain. Distal tibia fractures: management and complication of 101 cases. Int Ortho (SICOT). 2010; 34:583-588.

6. Olerud C, Molander H. A scoring scale for symptom evaluation after ankle fracture. Arch Orthop Trauma Surg. 1984; 103:190-4.

7. Rock Wood \& Green's: Fractures in Adults. 6th ed. Lippincot Williams \& wilkins; Philadelphia, 2006.

8. Sivasundaram L, Trivedi NN, Gatta J, Ning AY, Kim CY, Mistovich RJ. Demographics and Risk Factors for NonAccidental Orthopedic Trauma. Clin Pediatr (Phila). 2019; 58(6):618-626.

9. Viberg B, Kleven S, Hamborg-Petersen E, Skov O. Complications and functional outcome after fixation of distal tibia fractures with locking plate - A multicentre study. Injury. 2016; 47(7):1514-8. doi: 10.1016/j.injury.2016.04.025. Epub 2016 May 3.

10. Rathod SR, Shah DP, Solanki RA. Functional outcome of distal tibial fractures: Tibial nailing versus distal tibial locking plating. National Journal of Clinical Orthopaedics. 2018; 2(1):42-45.

11. Hasani I, Kaftandziev I, Stojmenski S et al. Two Stage Minimally Invasive Method with Locking Plate Application on Distal Tibia Fractures - Our Experience. Open Access Maced J Med Sci. 2017; 5(5):630-634. Published 2017 Jul 26. doi:10.3889/oamjms.2017.099 